\title{
FASCÍNIO NO MMA: O PAPEL DA REDE GLOBO NA CONSTRUÇÃO DO ÍDOLO ANDERSON SILVA (2010-2014)
}

\section{FASCINATING AT THE MMA: THE ROLE OF THE GLOBO NETWORK IN THE CONSTRUCTION OF IDOL ANDERSON SILVA (2010-2014)}

\author{
Fábio Ehlke Rodrigues*
}

\section{RESUMO}

O presente artigo investiga de que forma a mídia esportiva alavanca ídolos no esporte, através das contribuições de Hans Ulrich Gumbrecht sobre o fascínio. Neste estudo interdisciplinar, propomos verificar de que forma o fascínio contribuiu para que a Rede Globo transformasse em ídolo o lutador de MMA Anderson Silva no Brasil. Como a temática está relacionada à História do Tempo Presente, buscamos respaldo teórico-metodológico para sua melhor compreensão. Concluise, portanto, que a emissora conseguiu alavancar a carreira do atleta e popularizar o produto UFC no país.

Palavras-chave: Fascínio. Rede Globo. Anderson Silva.

\begin{abstract}
This article investigates how sports media leverage idols in sport through the contributions of Hans Ulrich Gumbrecht on fascination. In this interdisciplinary study, we propose to verify how the fascination contributed to the Rede Globo transforming MMA fighter Anderson Silva into the idol in the country. As the theme is related to the History of Present Time we seek theoretical-methodological support for your better understanding. It is, concluded, therefore, that the station managed to leverage the athlete's career and popularize the UFC product in the country.
\end{abstract}

Keywords: Fascinating. Globo Network. Anderson Silva.

\footnotetext{
"Especialista em História do Brasil -Ensino e Historiografia, CPGEX, Faculdades Integradas Espírita.
} 


\section{INTRODUÇÃO}

A nossa temática interdisciplinar se enquadra na História do Tempo Presente e se utiliza de sua metodologia para análise, devido à proximidade com o recorte temporal e o objeto de pesquisa - a mídia esportiva (Rede Globo e o ídolo do MMA ${ }^{1}$, Anderson Silva). Isto fica evidente quando a emissora de televisão passou a investir na popularização do esporte no Brasil. Por outro lado, fomos instigados a entender como este veículo de comunicação desempenhou um papel preponderante na construção de um fascínio nos espectadores e telespectadores sobre MMA e UFC ${ }^{2}$, segundo as contribuições de Hans Ulrich Gumbrecht, em Elogio da Beleza Estética (2007). A emissora procurou, dentro de uma estratégia de marketing, ampliar as aparições do Spider (Anderson Silva) nos seus programas de televisão, de esportes e jornais.

Neste artigo, por se tratar de pesquisa qualitativa, vamos nos ater às fontes da imprensa, localizadas em sites do jornal O Globo, da SporTv, do Globo Esporte e das mídias da emissora, no período de 2010-2014. Além disso, vamos nos embasar teoricamente nos estudos existentes sobre a temática Mídia Esportiva e MMA.

Para uma melhor compreensão de nossa intenção, realizamos, primeiramente, uma breve discussão sobre a História do Tempo Presente e sua metodologia. Em seguida, contextualizamos historicamente o MMA, traçamos uma trajetória da carreira do Spider e, então, analisamos o fascínio. Apesar de Gumbrecht apontar sete fascínios, que se entrecruzam, procuramos buscar três deles: corpos esculpidos, o sofrimento do atleta e a graça dentro daquilo que a Rede Globo se propôs para alavancar o MMA no país, utilizando-se da construção do ídolo Anderson Silva.

Ao analisar a questão dos corpos esculpidos, Gumbrecht nos leva a um passeio na Grécia, com a prática de exercícios físicos. Relacionado a isso, notamos que há uma rotina de treinamentos dos atletas do MMA: "ao longo de oito meses, eu me dedico aos treinos e compromissos da carreira" (SILVA, 2012, p. 153). A outra oportunidade é poder treinar na presença dos fãs em academias ou eventos preparados para promover a luta, que colocam ídolos e fãs cada vez mais pertos, algo bem explorado pela mídia esportiva.
Em relação ao sofrimento do atleta, Gumbrecht nos faz relatos históricos da carreira de Muhamad Ali e Joe Franzier. Anderson Silva citou em sua biografia e em entrevistas que se inspira em Ali para compor seu estilo de luta no boxe. Neste aspecto, analisamos uma luta do Spider e Chael Sonnen, no UFC 177, em que tudo parecia estar perdido para o atleta brasileiro, quando, nos trinta segundos finais, veio a glória e a superação do campeão, o que deixou a torcida em êxtase. Outro ponto investigado é a questão da preparação para a pesagem, que faz com que o atleta perca peso em pouco tempo, podendo causar riscos à saúde. Procuramos também tecer uma análise sobre o papel da Rede Globo na cobertura de um momento difícil na carreira de Anderson: a luta do dia 29 de dezembro de 2013 contra Chris Weidman, quando o lutador brasileiro fraturou a tíbia.

Já a questão da graça é entendida por Gumbrecht na vida esportiva de Ali. Analisamos isso nas performances do Spider em suas lutas, onde brincar com os adversários provocava euforia, mexia com as emoções dos torcedores e telespectadores, mas que também gerava críticas, inclusive de Dana White. Por outro lado, a graça do atleta rendeu participações nos programas da emissora Globo.

Para a Globo, além da popularização do MMA, também existia a mercantilização e a espetacularização do UFC (Ulthimate Fhigting Championship). No entanto, a exposição exagerada do esporte também pode causar o vício.

Para viciar no esporte, basta uma distância entre o atleta e o espectador - uma distância grande o suficiente para fazer o espectador acreditar que seus heróis vivem em outro mundo. É assim que os atletas se transformam em objetos de admiração e desejo. (GUMBRECHT, 2007, p. 15-16).

Para finalizar esta parte introdutória, deixamos duas questões elaboradas por Gumbrecht (2007, p. 24) a serem pensadas: Por que os amantes do esporte deveriam aprender a elogiar os atletas e suas conquistas? A pergunta aponta para duas direções: Existe uma necessidade de elogiar os atletas ou basta que gostemos de assistir ao que eles fazem?

${ }^{1}$ MMA (Artes Marciais Mistas).

${ }^{2}$ UFC (Ultimate Fight Championship). 


\section{A HISTÓRIA DO TEMPO PRESENTE, SUAS POSSIBILIDADES TEÓRICO- METODOLÓGICAS E A IMPRENSA}

Antes de mais nada, se faz necessário buscar definições sobre o que é a História do Tempo Presente, sua importância histórica e entender como a imprensa se insere no seu foco de análise. Voltamos, então, à definição apresentada por Jean Pierre Rioux (1999, p. 50): "um vibrato do inacabado que anima o passado, um presente aliviado de seu autismo, uma inteligibilidade perseguida fora de alamedas percorridas, é um pouco isto, a História do Tempo Presente".

Recorremos a outros autores e encontramos as seguintes questões por eles abordadas. "A própria definição da história do tempo presente é ser a história de um passado que não está morto, de um passado que ainda serve da palavra e da experiência de indivíduos vivos" (ROUSSO, 1998, p. 63). Já para François Dosse (2012), a História do Tempo Presente se utiliza de testemunhos, imagens, entrevistas, imprensa, a literatura acessada e não acessada (pelo grande público e os arquivos privados). Mais além, articula que os historiadores do tempo presente "tem a necessidade, para realizar com maior êxito suas pesquisas, de trabalhar com os cientistas políticos, jornalistas, sociólogos, geógrafos, psicanalistas, antropólogos e críticos literários" (DOSSE, 2012, p. 14).

É de salutar importância a criação do Institut d'Historie du Temp Present, na França, no qual François Dosse é pesquisador associado e o Institut d'Historie Moderne et Contemporanie, em 1978, pelo Centre National de la Recherche Scientifique (CNRS).

Mas de que forma o historiador deve proceder ao se apropriar dos pressupostos teórico-metodológicos da História do Tempo Presente? Uma das respostas consiste em "pôr a História em perspectiva depois de ter retirado desta os aspectos factuais que são apenas a sua trama" (CHAVEAU; TÉTART, 1999, p. 27).

É nas palavras de Chaveau e Tétart que inserimos nosso objeto de pesquisa, a imprensa, que está enraizada em um conjunto de práticas que influi no mercado editorial, nas pautas e nos conteúdos a serem abordados no jornal. No entanto, devemos levar em conta a subjetividade do historiador, algo presente na História do Tempo Presente. Podemos citar o que nos aponta Carlos Ginzburg (1989), que o historiador deve buscar os indícios ou pistas, baseado no paradigma indiciário.

Seguindo as análises de François Dosse, elencamos alguns pontos interessantes da teoria-metodológica da História do Tempo Presente:

o primeiro, o historiador é sempre questionado e é levado a pensar por si próprio, segundo ponto, a ele cabe encontrar a indeterminação do presente das sociedades passadas, levando-o a uma reavaliação da contingência, da pluralidade das possibilidades, da diversidade da escolha dos possíveis atores, terceiro ponto, é a importância das testemunhas em sua construção, quarto fator, é que essa história está sob vigilância, de as testemunhas que podem contestar os registros históricos nos quais não se reconhecem, o que torna ainda mais necessária uma estrita articulação entre História e Memória. (DOSSE, 2012, p. 15).

\section{CONTEXTUALIZAÇÃO DO MMA E A TRAJETÓRIA DE ANDERSON SILVA}

A história do MMA tem origem por volta de 1917, com a chegada ao Brasil do mestre de judô Mitsuo Maeda, que passou a ensinar a família Gracie, entre eles, Hélio Gracie. Com ele, difundiu-se o JiuJitsu Brasileiro. Em meados dos anos 50, os desafios da família Gracie começaram a se tornar espetáculos de Vale-Tudo. Em 1970, Rorion Gracie, filho de Hélio, foi morar nos Estados Unidos, onde difundiu o jiu-jitsu brasileiro para o resto do mundo.

Em 1994, Rorion Gracie e seu aluno, Art Davis, articularam a visibilidade do UFC em lutas transmitidas pelo sistema pago de TV nos EUA, o pay-per-view. Em 1997, o evento Pride, no Japão, começa a ter destaque e dá-se início a profissionalização do vale-tudo e a transição para o MMA(NETO, 2016). Nos anos de 2001 a 2016, a organização pertenceu aos irmãos Fertitta e Dana White, que comprou os direitos de Rorion Gracie por US\$ $2 \mathrm{mi}$, passando para a administração da ZUFFA (TATAMEONLINE, 2017).

Em 2005 foi criado o The Ultimate Fighter, o primeiro reality show de MMA, com o intuito de popularizar o esporte. Em 2007, a ZUFFA começa a tomar conta do Pride, que em outubro do mesmo ano foi fechado, pois os melhores lutadores do torneio asiático foram trazidos para o UFC (TATAMEONLINE, 
2017a). E como tudo isso está relacionado com Anderson Silva?

Anderson Silva nasceu em São Paulo/SP no dia 14 de abril de 1975, e, aos quatro anos de idade, muda-se para Curitiba/PR. Com 14 anos começa a aprender taekwondo, obtendo a faixa preta aos 18 anos. Dedicase também ao Muay Thai, Jiu-Jitsu, Boxe, Judô e Capoeira. Aos 22 anos, em 25 de junho de 1997, inicia sua carreira no MMA, no evento "Brazilian Freestyle Circuit 1", em Campo Grande, Mato Grosso do Sul, onde finalizou Raimundo Pinheiro e venceu Fabrício "Morango" Camões por nocaute técnico (SPORTV, 2013a). Em 27 de maio de 2000 teve sua primeira derrota no evento "Mecca World Vale Tudo 1", perdendo para Luiz Azeredo. A partir de 2001 inicia uma série de vitórias no Shooto.

A sua estreia no Pride, em 2002, ocorreu com vitória sobre Alex Stiebling, conhecido como "Brazilian Killa" ("Matador de Brasileiros"), após a impressionante marca de ganhar de seis brasileiros. Anderson desferiu vários outros golpes, mas com uma canelada no rosto, abriu o supercílio do americano. Logo, a luta foi interrompida para atendimento médico e o combate foi encerrado (SPORTV, 2012).

O próximo adversário do Spider no Pride 25, em 2003, foi o canadense Carlos Newton, ex-campeão peso médio do UFC. A vitória ocorreu por nocaute com joelhadas, voadoras e socos. Em 2004, já pelo Cage Rage 8, na luta pelo cinturão dos médios, foi a vez de Lee Murray ser derrotado.

A estreia no UFC (evento UFC Ultimate Fight Night 5) ficou marcada por mais uma vitória por nocaute com uma joelhada em Chris Leben, no dia 28 de junho de 2006. Ainda em 2006, Anderson venceu Rich Franklin e conquistou o cinturão dos médios do UFC.

Por volta de 2008, outras vitórias marcaram a carreira de Anderson Silva. A primeira delas, contra Dan Henderson, permitiu a unificação dos cinturões do Pride e UFC (evento UFC 82) e a segunda, desta vez contra James Irvin, na categoria meio pesado do UFC. (SILVA, 2012, p. 158). Vieram outras lutas com vitórias, duas delas em 2009, uma contra Thales Leites, no UFC 97, e Forrest Griffin, por nocaute com soco pelo UFC 101. Em 07 de agosto de 2010 um dos grandes desafios do Spider era defender o cinturão dos médios e o desafiante era Chael Sonnen. Mais uma vitória, desta vez por finalização (triângulo).
Apesar da 9ine já vir agenciando a imagem do atleta desde 2010, a carreira de Anderson começa a mudar a partir da luta contra Vitor Belfort em 05 de fevereiro de 2011, um nocaute com um chute frontal certeiro aplicado por Anderson Silva. O confronto teve três minutos de combate. É a partir daí que começa a transformação do desconhecido à ídolo do país.

Feita a contextualização do MMA e a trajetória de Anderson Silva, passamos a investigar o fascínio nas contribuições de Hans Ulrich Gumbrecht e sua relação com a construção do ídolo Spider pela Rede Globo.

\section{FASCÍNIO}

O conceito de fascínio para Hans Ulrich Gumbrecht (2007, p. 109) se refere ao olhar que é atraído - e até paralisado - pelo apego de algo que é percebido, em nosso caso a performance atlética. Mas ela também capta a dimensão adicional da contribuição do espectador.

Gumbrecht cita sete fascínios distintos: corpos esculpidos, sofrimento diante da morte, graça, instrumentos que aumentam o potencial do corpo, formas personificadas, jogos como epifanias e timing. Nossa análise, como bem disse Gumbrecht, perpassa por estes fascínios, que, muitas vezes, se misturam. No entanto, sua divisão ocorre de uma forma mais didática.

\section{CORPO}

Os corpos esculpidos através do exercício físico nas academias e a preparação dos atletas de MMA, mediante a treinos que levam à exaustão, podem ser comparados "àquele espaço cercado de colunas de um ginásio da Grécia Antiga, onde cidadãos e seus filhos esculpiam seus corpos com exercícios" (GUMBRECHT, 2007, p. 110).

Na preparação para o UFC 153 (UFC Rio III), o treino foi aberto

[...] e contou com a presença de 1000 pessoas nos Arcos da Lapa, mas para uma delas ganhou contornos especiais. Com um cartaz de Anderson Silva na mão, Nasha Fraga da Silva, de 14 anos, ganhou permissão do lutador para acompanhar de perto a atividade feita pelo Spider e se emocionou ao ganhar um abraço do ídolo. (ALBUQUERQUE; KESTELMAN, RAUPP, 2012). 
Em outra ocasião, no dia 28 de março de 2014, após a lesão na luta contra Chris Weidman, em 29 de dezembro de 2013, Anderson busca a recuperação para voltar ao octógono na academia no Rio, na Barra da Tijuca e os fãs param de malhar para vê-lo.

Por onde passa, Anderson Silva atrai olhares de fãs e curiosos. Até mesmo quando treina em uma academia, o ex-campeão do UFC se torna o centro das atenções. Foi o que aconteceu na noite desta sexta-feira, na Body Tech do Shopping Cittá América, na Barra da Tijuca, Zona Oeste do Rio de Janeiro. Enquanto treinava muay thai e jiu-jitsu, Spider parou a academia e atraiu uma plateia, inclusive quem estava malhando no local, só para vê-lo aplicar alguns golpes. (EXTRA, 2014).

\section{SOFRIMENTO DO ATLETA}

Nada poderia estar mais longe do clima do ginásio grego da Antiguidade que um ringue moderno do boxe. As cordas que cercam o ringue se envolvem e mal contêm uma paixão direta e destrutiva, as consequências devastadoras da violência desenfreada de atletas e espectadores. (GUMBRECHT, 2007, p. 113).

O pugilismo representa, no ringue, poucas limitações, é o confronto dos lutadores com a morte em potencial. Assim como os gladiadores romanos, os pugilistas só conquistarão a admiração e o amor da multidão se tiverem estado na situação dramática de enfrentar a possibilidade de sua destruição física pessoal. (GUMBRECHT, 2007, p. 113-114). Mas, se a principal atração do boxe é a proximidade do lutador com a morte, isso não significa que a inteligência estratégica, o talento técnico e, acima de tudo, a graça nos movimentos estejam excluídos dos atributos que fazem os pugilistas brilharem na percepção de seus fãs.

No entanto, as lutas que deram origem ao status incomparável de Muhammad Ali na história do boxe, por exemplo, foram as lutas em que ele sofreu a ponto de estar à beira da destruição física. (GUMBRECHT, 2007, p. 116).

Lembro-me dos três combates dele contra Joe Frazier e principalmente da luta épica de um Ali já mais velho contra o jovem e fisicamente superior campeão mundial George Foreman, que aconteceu na capital do Zaire, Kinshasa, no dia 30 de outubro de 1974 (essa luta transformou-se no episódio central do filme Ali). Apoiado nas cordas de propósito, deslizando e esquivando-se o melhor que podia (estratégia que Ali chamou de "rope-a dope"), e recebendo golpes brutais, a maioria na caixa torácica, durante sete assaltos, Muhammad Ali inverteu a dinâmica do combate no oitavo assalto, quando, como se do nada, atingiu Foreman de forma com um gancho de esquerda, um direito de direita na mandíbula e outro gancho de esquerda. Nessa luta e no próximo confronto - uma vitória com uma vantagem estreita sobre Joe Frazier, que Ali descreveu como "o mais perto da morte que já estive" -, ficou claro, de uma vez por todas, onde está o fascínio no boxe. Trata-se de sofrer até chegar à morte, para então, se possível, voltar da experiência de quase-morte e assumir um domínio físico decisivo. (GUMBRECHT, 2007, p. 117).

O exemplo de Muhamad Ali nos remete a uma alusão ao personagem Rock Balboa, vivido nos cinemas por Silvester Stallone. "Rock" para os telespectadores parecia um atleta quase derrotado, estendido no chão, após uma sequência de golpes violentos, mas, buscando uma força fenomenal, ele se levanta e nocauteia os seus oponentes.

Algo parecido aconteceu na vida de Anderson Silva e nos ajuda a tensionar com Gumbrecht tal posicionamento.

A primeira luta, do UFC 117, foi eleita a melhor de 2010, e Sonnen chocou o mundo ao abalar Silva em pé e dominar o combate por quatro rounds e meio, até o paulista encaixar um triângulo nos minutos finais e finalizar para quebrar o recorde de defesas de cinturão da organização. (SPORTV, 2015).

Todos os esportes que provocam um confronto direto entre dois oponentes - um duelo, no sentido mais literal - reproduzem uma cena em que a tranquilidade diante dos gestos de destruição é o ponto alto da produção. Isso certamente se aplica à luta livre, em que fugir da imobilização é quase tão bom quanto um empate. (GUMBRECHT, 2007, p. 117).

No esporte, o torcer causa sofrimento e um borbulhar de emoções que variam de intensidade, pelo qual passa o torcedor e o telespectador que decide acompanhar as lutas do MMA, principalmente, se o seu ídolo está no octógono.

Pelo UFC 168, no MGM Grand Garden Arena, lutavam Anderson Silva e Chris Weidman no dia 29 de dezembro de 2013, até que 
O atleta brasileiro sofreu uma fratura chocante na perna esquerda ao aplicar um chute em Chris Weidman no segundo round, foi ao chão na sequência e não pôde prosseguir no duelo. Sentindo muita dor, ele deixou o octógono de maca, com a perna imobilizada e foi direto para o hospital. Declarado vencedor por nocaute técnico devido à lesão do oponente, Weidman manteve o título peso-médio (até $84 \mathrm{~kg}$ ) da organização. O americano, por sinal, estava bem até aquele momento e havia sido bem superior no primeiro assalto. $\mathrm{O}$ episódio é um duro golpe para Anderson, que diferentemente do primeiro encontro, quando foi de fato nocauteado por Weidman após fingir que havia sido atingido, estava lutando de forma séria e sem fazer provocações. Foi a sexta derrota na carreira do atleta de 38 anos num total de 39 combates. Já Weidman, de 29 anos, aumentou seu cartel invicto para 11 triunfos. (ALBUQUERQUE; RODRIGUES, RAUPP, 2013).

O G1 (2013), em seu site, publicou "Lesão deixa futuro incerto para carreira de Anderson Silva". E o Jornal Nacional, no dia 30 de dezembro de 2013, fez uma cobertura jornalística direto do Centro Médico Universitário de Las Vegas, nos Estados Unidos, e trouxe um panorama sobre a cirurgia e a recuperação do atleta. A questão principal da reportagem foi deixada para o final com uma indagação: "É grande a expectativa para saber sobre os planos futuros de Anderson Silva, se ele vai continuar ou não lutando, já que a recuperação deve levar pelo menos seis meses" (FANTÁSTICO, 2013a).

Em entrevista polêmica, a primeira após a lesão, Anderson Silva fala ao Fantástico, no dia 12 de janeiro de 2014. O Fantástico enviou a repórter Renata Ceribelli para Los Angeles para conversar com o atleta. A Globo destinou 12 minutos do programa para entrevista. Ele é mostrado ao lado da família e respondeu sim ao ser questionado se voltaria a lutar. Também falou da dor na hora da lesão, do medo que sentiu até a hora de ser levado ao hospital e de suas dúvidas em relação ao que o médico poderia dizer sobre voltar ou não. Para a família, é grande a vontade de que Anderson pare de lutar (FANTÁSTICO, 2014).

Essa ligação entre o profissional lutador e o homem de família engrandece a imagem de herói que a mídia trabalhou e continua trabalhando sobre o personagem Anderson Silva. No campo esportivo do MMA, em conjunto à publicidade do lutador, o resultado é tão positivo quanto a grande visibilidade alcançada.
Portanto, a ideologia sobre a massa de espectadores está na especulação de um marketing que vai além do esporte, coloca em pauta a vida do atleta como meio de alcançar maior proximidade com o público. "Em termos ideológicos, o campeão heroico é aquele que trabalhou muito, galgou os degraus da hierarquia esportiva e, portanto, da pirâmide social: o esporte é a poesia da hierarquia". (BROHM, 1978 apud BETTI, 1998, p. 184).

O papel dos meios de comunicação de massa proporciona uma maior visibilidade dos atletas e também dos seus patrocinadores através das campanhas publicitárias. Bourdieu (1997) destaca que a imagem televisiva do espetáculo obedece às lógicas de mercado, porque é suporte para a publicidade de marcas de patrocinadores e apoiadores do evento em transmissão. É mister que a imagem do esporte na televisão seja atraente e cativante para o público a quem será exibida em horários de grande audiência para as emissoras de TV.

A idolatria construída pela Rede Globo também durante a lesão pode ser percebida nas redes sociais, em que os fãs de Anderson Silva as utilizam para manifestar seu apoio no período de recuperação. Apesar de estar afastado dos treinos e dos ringues, em 22 de março de 2014 aparece no Programa Altas Horas, de Serginho Groisman, para anunciar que estaria de volta ao octógono em 2015 (ALTAS HORAS, 2014).

A lesão trouxe prejuízos ao Spider, uma vez que alguns patrocinadores se afastaram, como ele mesmo afirma em reportagem ao Sportv Repórter.

Tiveram alguns patrocinadores que deram para trás. Infelizmente é assim que funciona. Mas têm alguns que estão comigo até hoje, que me apoiaram. Eu acho que a grande relação que tem que ter entre patrocinador e atleta são a parceria a longo prazo. Independente de o atleta estar ou não lutando, o que tem que ser bem trabalhado é a imagem da marca que está patrocinando e a imagem do atleta - disse. (SPORTV, 2014).

Outro ponto de destaque que causa o sofrimento no atleta está relacionado à pesagem dos lutadores do UFC antes da luta. Os atletas têm que perder uma grande quantidade de peso, o que pode levar a sérios riscos à saúde.

Em reportagem publicada pela Revista Veja, em 8 de agosto de 2011, o jornalista Davi Correia explica como é o processo da perda de peso. 
Diogo Souza, preparador físico do Team Nogueira, conta que a dieta é determinada por uma nutricionista e muda com a proximidade da luta. "É tudo controlado: à noite, raramente se consome carboidrato; aminoácido só no caso de muito desgaste, e sempre há proteína após o treino". O procedimento varia de acordo com o biotipo do lutador. Alguns tem mais facilidade em perder peso, caso do campeão do peso-médio Anderson Silva: ele chega a se livrar de dezesseis quilos para a pesagem e repõe o necessário para chegar 'forte à luta'. "A redução drástica não é aconselhada para todo atleta. Alguns sais minerais serão repostos apenas 66 horas depois", explica Souza. E, claro, tudo isso, tem um custo e compromete tanto o físico como o psicológico. O baixo nível de carboidrato deixa os atletas mais estressados e baixa a imunidade. Não é raro, os atletas lutarem com febre ou amidalite, por exemplo. (CORREIA, 2011).

\section{GRAÇA}

A graça pertence àqueles conceitos que, quando examinados e pensados à fundo, revelam sacadas surpreendentes e uma complexidade insuspeita. Em seu ensaio "Ueber das Marionetttheater" (Sobre o Teatro de Marionetes), escrito em 1810, Henrich Von Kleist, um dos maiores escritores da tradição literária alemã, desenvolveu uma compreensão da graça que nos ajuda a analisar o fascínio que essa característica representa para os verdadeiros amantes do esporte.

O diálogo ficcional de Kleist começa com um famoso bailarino confessando o quanto sempre gostou de assistir às marionetes e como vê aqueles movimentos como modelo para sua própria performance. (GUMBRECHT, 2007, p. 119). Em vez de enfatizar as formas e os movimentos que as marionetes têm em comum com o corpo humano, o bailarino as elogia por pertencerem "ao universo das artes mecânicas". A graça, Kleist nos faz entender, é o produto do distanciamento do corpo e de seus movimentos em relação à consciência, à subjetividade e à sua expressão. (GUMBRECHT, 2007, p. 120).

Em 12 de abril de 2010, uma reportagem do jornal O Globo colocava em cheque a carreira do lutador. Durante a luta de Anderson Silva e Demian Maia, o Spider recebeu fortes críticas de Dana White, presidente do UFC, pois desrespeitou o adversário e dançou dentro do octógono.
Ninguém apoiou Anderson mais do que eu. Acho que ele tem muito talento, mas se você tem tanto talento, seja como Mike Tyson. Derrote o outro cara em dois minutos ao invés de ficar brincando como um idiota por cinco rounds. Foi a coisa mais horrível que já vi. Não sei por que ele agiu daquele jeito. $\mathrm{O}$ pior é que ele acha que não precisa se desculpar com os fãs. Eu estou pedindo desculpas, e eu não agi como um idiota durante os cinco rounds - completou Dana, que revelou que deixou a luta antes do fim. Ele não entregou o cinturão para Anderson após a luta. (O GLOBO, 2010).

A graça, como objeto de uma experiência estética, faz-nos lembrar as vezes que fomos incapazes, devo acrescentar, de associar os movimentos do corpo que vemos às intenções ou pensamentos daqueles que os executam. (GUMBRECHT, 2007, p. 120).

Em muitas das lutas de Anderson Silva a graça foi usada como estratégia para provocar seus adversários. Em algumas delas, os fãs iam ao êxtase com a vitória, mas também às frustrações e sofrimentos em casos de derrotas. Na luta do UFC 162, contra Chris Weidman, Anderson Silva exagerou da graça, o que o levou à derrota.

Após baixar a guarda e pedir para Weidman golpeá-lo, Anderson fingiu rir do adversário, colocou as mãos na cintura e chamou o americano para a luta, pedindo que o golpeasse. No fim do round, um beijo encerrou as ações. No início do segundo round, Anderson chamou Weidman para a luta, pedindo que o americano lutasse. Mas exagerou nas provocações, e perdeu o foco no combate. Dando o rosto para ser golpeado, o brasileiro fingiu tremer, dançou e riu, mas não contava com um cruzado de esquerda seguido por uma sequência de socos que o derrubaram e forçaram o árbitro Herb Dean a encerrar o combate. (SPORTV, 2013).

A graça e a violência muitas vezes caminham juntas. Os movimentos de Muhamad Ali não teriam perdido nada de sua graça se ele tivesse sido um boxeador mais agressivo. (GUMBRECHT, 2007, p. 122). Muhamad Ali serviu de inspiração para Anderson Silva compor seu estilo de luta. Em sua biografia, ele faz menção ao fato de que "tenho um grande exemplo que é o ex-campeão mundial dos pesos pesados Muhammad Ali. Sempre vejo suas lutas e as do ex-campeão mundial Roy Jones Jr. Sempre. Vi as lutas de Ali contra Joe Frazier e George Foreman" (SILVA, 2012, p. 116). 
A graça também levou a Globo a colocar o Spider em seus programas televisivos. O atleta esteve no Caldeirão do Huck em 15 de outubro de 2011, fazendo uma imitação de Justin Bibier no palco, no quadro "Lata Velha", para ajudar a Associação de Pais e Amigos dos Excepcionais (APAE), de Montes Claros, Minas Gerais (SPORTV, 2011).

\section{CONCLUSÕES}

Nosso propósito com este artigo foi verificar a metodologia através da História do Tempo Presente, tecendo uma discussão com historiadores franceses, inclusive com François Dosse e Jean Pierre Rioux. Apresentamos um breve histórico do MMA, analisando as origens do Vale Tudo com o jiu-jitsu brasileiro, da família Gracie até a compra do UFC pelos irmãos Fertitta. Traçamos a trajetória da carreira do lutador Anderson Silva, seu início de carreira no Paraná e suas passagens pelo Pride até chegar ao UFC.

Por conseguinte, abordamos de que forma a Rede Globo se utilizou do fascínio para popularizar o MMA e Anderson Silva no Brasil, tendo como base as contribuições teóricas de Hans Ulrich Gumbrecht, pelo qual analisamos três dos sete fascínios: corpos esculpidos, sofrimento diante da morte e graça. Identificamos também como a referida emissora de televisão usou destes recursos como estratégia de mídia esportiva na exibição das lutas e na exposição da imagem do atleta na sua programação e nos jornais online.

Para isso, nos propusemos a debater com Gumbrecht nos momentos oportunos, utilizando-o como base para o referencial teórico. Voltamos no tempo da Grécia para historicizar o fascínio pelos corpos esculpidos, nos mitos do boxe, Muhammad Ali e Joe Frazier, o que nos possibilitou analisar a questão do sofrimento do atleta. Neste aspecto, quando tudo parece estar perdido, o atleta renasce como a Fênix e acaba vencendo a luta. Isso ocorreu na luta entre Anderson Silva e Chael Sonnen, no UFC 117, em 2010, onde o Spider foi surpreendido durante quatro rounds e meio e nos trinta segundos finais aplicou um triângulo e se sagrou campeão, e na lesão sofrida por Anderson Silva na luta contra Chris Weidman em dezembro de 2013. Nesses casos, a Globo fez questão de criar um cenário específico para o ídolo do MMA.
Atentamos também para a questão da graça, uma peculiaridade de Anderson Silva, que resultou em críticas, mas que propiciou momentos de emoção nos espectadores que estavam presentes nas lutas e até naqueles telespectadores que vibraram em suas casas nas transmissões do UFC pela Rede Globo.

O espetáculo dos lutadores do UFC nas Arenas pode ser comparado à luta dos gladiadores no Coliseu Romano. Gumbrecht (2007, p. 77-78) aponta que “o histórico de vitórias e derrotas era anunciado assim que ele aparecia na arena, o que indica que naquele mundo brutal existia uma aura comparável ao estrelato esportivo da atualidade".

Para finalizar, gostaríamos de registrar duas questões. A primeira baseada em "A Ode sobre Teron de Acragás", de Píndaro:

\section{(...) Vencer}

Liberta das ansiedades aquele que compete.

Em verdade, a riqueza adornada de virtudes oferece oportunidade para várias conquistas ao sustentar profunda e insistente ambição;

É estrela-guisa visível, a mais verdadeira luz para o homem. (GUMBRECHT, 2007, p. 73).

E a segunda, algo que encontramos na biografia de Anderson Silva:

Eu me sentiria feliz se os fãs do MMA tivessem sempre em mente que somos praticantes de uma atividade cuja filosofia prega o respeito ao próximo. Uma filosofia que nada tem a ver com violência, mas com respeito e honra. A arte marcial fez de mim uma pessoa melhor. Eu gostaria que ela inspirasse da mesma forma todos os que amam o UFC. (SILVA, 2012, p. 157).

\section{REFERÊNCIAS}

ADAMI, Antonio; HELLER, Barbara; CARDOSO, Haydee Dourado de Faria. Mídia, Cultura e Comunicação. São Paulo: Arte \& Ciência, 2003.

ALVAREZ, Fábio de Lima; MARQUES, José Carlos. Entre Tapas e Beijos: A Humanização "Fantástica" do lutador de MMA Anderson Silva pela Rede Globo de Televisão. In: CONGRESSO BRASILEIRO DE CIÊNCIAS DA COMUNICAÇÃO, 36, 2013, Manaus. Anais... Manaus: Intercom, 2013.

O MMA e a busca de identidade em uma cultura em vias de globalização. In: CONGRESSO BRASILEIRO 
DE CIÊNCIAS DA COMUNICAÇÃO, 35, 2012, Fortaleza. Anais... Fortaleza: Intercom, 2012.

ALVES, Carolina de Miranda Pineli; CARLI, Maria Fernanda Nedochetko. UFC Combate: uma experiência estética. Revista Temática, v. 8, n. 11, nov. 2012. Disponível em: $\quad<\mathrm{http}: / /$ periodicos.ufpb.br/index.php/tematica/article/ view/23153>. Acesso em: 26 out. 2017.

AWI, Felipe. Filho teu não foge a luta. Rio de Janeiro: Intrínseca, 2012.

BETTI, Mauro. A janela de vidro: esporte, televisão e Educação Física. Campinas, SP: Papirus, 1998.

BOURDIEU, Pierre. Sobre a Televisão. Rio de Janeiro: Jorge Zahar, 1997.

CHAUVEAU, Agnès; TÉTART, Philppe. Questões para a história do presente. Trad. Ilka Stern Cohen. Bauru: EDUSP, 1999.

DOSSE, François. História do tempo presente e historiografia. Revista Tempo e Argumento, Florianópolis, v. 4, n. 1, p. 5-22, jan./jun. 2012.

FRANZONI, Sabrina; STEFANI, Andreza Domingues. Além do Octógono: a imagem de Anderson Silva em programação não esportiva na TV. Vozes \& Diálogo, Itajaí, v. 12, n. 1, p. 47-61, jan./jun. 2013.

GINZBURG, Carlo. Mitos, emblemas e sinais: morfologia e história. Trad. Frederico Carotti. São Paulo: Companhia das Letras, 1989.

GORITO, Andréia de Vasconcelos. The Ultimate Fighter Brasil: a espetacularização do MMA pela mídia e seus desdobramentos. In: CONGRESSO BRASILEIRO DE CIÊNCIAS DA COMUNICAÇÃO, 35, 2012, Fortaleza. Anais... Fortaleza: Intercom, 2012.

GUMBRECHT, Hans Ulrich. Elogio da beleza atlética. São Paulo: Companhia das Letras, 2007.

HELAL, Ronaldo; AMARO, Fausto. Esporte e Mídia: novas perspectivas - A influência das obras de Hans Ulrich Gumbrecht. Rio de Janeiro: EdUERJ, 2015.

MIRANDA, Fernanda de Alvarenga. O MMA no Brasil: um panorama da modalidade. Esporte e Sociedade, ano 7, n. 20, set. 2012.

MIRANDA FILHO, Vamberto Ferreira; SANTOS, Igor Sampaio Pinho dos. A influência da mídia na mercadorização do MMA. Lecturas Educación Física y Deportes, Buenos Aires, v. 18, p. 1-9, 2014.

NETO, Álvaro Rego Millen; GARCIA, Roberto Alves; VOTRE, Sebastião Josué. Artes marciais mistas: lutas por afirmação e mercado de luta. Revista Brasileira de Ciências do Esporte, Porto Alegre, v. 38, n. 4, out./dez. 2016.
RIOUX, Jean-Pierre. Pode-se fazer uma história do presente? In: CHAUVEAU, A., TÉTART, P. (Orgs.). Questões para a história do presente. Bauru, SP: EDUSC, 1999.

ROUSSO, Henry. La hantise du passé. Entretien avec Philippe Petit, les Editions. Textuel, 1998.

SANTOS, Igor Sampaio Pinho dos; MIRANDA FILHO, Vamberto Ferreira. Considerações sobre mídia e "heróis esportivos" do mixed martial arts. Motrivivência, Florianópolis, v. 27, n. 44, p. 207-218, maio. 2015.

SILVA, Anderson. Anderson Spider Silva: o relato de um campeão nos ringues e na vida / depoimento a Eduardo Ohata. Rio de Janeiro: Sextante, 2012.

SPINDOLA, Guilherme Caleffi; DANTAS, Sérgio Silva. Participação da mídia no contato do público paulistano com o MMA. Iniciação Científica Cesumar, Maringá, v. 17, n. 2, p. 145-157, jul./dez. 2015.

\section{FONTES}

ALBUQUERQUE, Adriano; RODRIGUES, Evelyn; RAUPP, Ivan. Anderson sofre fratura chocante em chute, e Weidman mantém cinturão. Sportv, Las Vegas, 29 dez.2013. Disponível em: <http://sportv.globo.com/site/combate/ noticia/2013/12/anderson-silva-sofre-fratura-exposta-emchute-e-weidman-mantem-o-titulo.html>. Acesso em: 27 out. 2017.

ALBUQUERQUE, Adriano; KESTELMAN, Amanda; RAUPP, Ivan. Fã assiste a treino de Anderson de Perto e se emociona com abraço. Sportv, Rio de Janeiro, 10 ago. 2012. Disponível em: <http://sportv.globo.com/site/combate/ noticia/2012/10/fa-assiste-treino-de-anderson-de-perto-ese-emociona-com-abraco.html>. Acesso em: 28 out. 2017.

ALTAS HORAS. Entrevista de Anderson Silva a Serginho Groisman, 22 mar. 2014. Disponível em: <https://globoplay. globo.com/v/3232664/>. Acesso em: 27 out. 2017.

ANDERSON Silva agradece a Chael Sonnen: "Você mudou a minha vida". Sportv, Las Vegas, 01 fev. 2015. Disponível em: <http://sportv.globo.com/site/combate/noticia/2015/02/ anderson-silva-agradece-chael-sonnen-voce-mudou-minhavida.html>. Acesso em: 27 out. 2017.

ANDERSON Silva diz para agente que ninguém merece sentir dor que sentiu. G1, 30 dez. 2013. Disponível em: $<$ http://g1.globo.com/jornal-nacional/noticia/2013/12/ anderson-silva-diz-para-agente-que-ninguem-merece-sentirdor-que-sentiu.html>. Acesso em: 27 out. 2017.

ANDERSON Silva tira foto do baú para relembrar primeira luta: 'Tinha 75kg'. Sportv, Rio de Janeiro, 06 jan. 2013a. Disponível em: <http://sportv.globo.com/site/combate/ noticia/2013/01/anderson-silva-tira-foto-do-bau-para- 
relembrar-primeira-luta-tinha-75kg.html $>$. Acesso em: 27 out. 2017.

ANDERSON Silva treina em academia na Barra da Tijuca e fãs param de malhar para vê-lo. Extra, Rio de Janeiro, 28 mar. 2014. Disponível em: <https://extra.globo.com/ esporte/lutas/anderson-silva-treina-em-academia-na-barrada-tijuca-fas-param-de-malhar-para-ve-lo-12026192.html . Acesso em: 28 out. 2017.

CORREIA, Davi. Atletas da UFC perdem até $16 \mathrm{~kg}$ para 'enganar' a balança. Veja, 08 ago. 2011. Disponível em: $<$ http://veja.abril.com.br/esporte/atletas-do-ufc-perdem-ate16-kg-para-enganar-a-balanca/>. Acesso em: 27 out. 2017.

Entrevista de Anderson Silva para Renata Ceribelli, Fantástico, 24 jan. 2014. Disponível em: <https://globoplay. globo.com/v/3073242/>. Acesso em: 28 out. 2017.

Anderson Silva diz para agente que ninguém merece sentir dor que sentiu. Fantástico, $30 \mathrm{dez}$. 2013a. Disponível em: $<$ http://g1.globo.com/jornal-nacional/noticia/2013/12/ anderson-silva-diz-para-agente-que-ninguem-merece-sentirdor-que-sentiu.html>. Acesso em: 27 out. 2017.

LESÃO deixa futuro incerto para carreira de Anderson Silva. G1, 29 dez. 2013. Disponível em: <http://g1.globo.com/ fantastico/noticia/2013/12/lesao-deixa-futuro-incerto-paracarreira-de-anderson-silva.html> . Acesso em: 27 out. 2017.

POR motivo nobre, Anderson Silva encarna Justin Bieber no palco. Sportv, Rio de Janeiro, 15 out. 2011. Disponível: $<$ http://sportv.globo.com/site/combate/noticia/2011/10/ por-motivo-nobre-anderson-silva-encarna-justin-bieber-nopalco.html>. Acesso em: 27 out. 2017.

PRESIDENTE do UFC critica fortemente Anderson Silva. O Globo, Rio de Janeiro, 12 abr. 2010. Disponível em: $<\quad$ https://oglobo.globo.com/esportes/presidente-do-ufccritica-fortemente-anderson-silva-3025281>. Acesso em: 27 out. 2017.

RETROSPECTIVA: as cinco melhores lutas de Anderson Silva e Sonnen. Sportv, Rio de Janeiro, 27 jun. 2012. Disponível em: <http://sportv.globo.com/site/combate/ noticia/2012/06/retrospectiva-cinco-melhores-lutas-deanderson-silva-e-sonnen.html>. Acesso em: 27 out. 2017.

SPIDER revela perda de patrocinadores após grave lesão. Sportv, Rio de Janeiro, $24 \mathrm{dez}$. 2014. Disponível em: $<$ http://sportv.globo.com/site/programas/sportv-reporter/ noticia/2014/12/spider-revela-perda-de-patrocinadoresapos-grave-lesao-deram-para-tras.html $>$. Acesso em: 27 out. 2017.

WEIDMAN luta sério, faz o impossível e vence Anderson Silva por nocaute. Sportv, Los Angeles, 07 jul. 2013. Disponível em: <http://sportv.globo.com/site/combate/ noticia/2013/07/chris-weidman-faz-o-impossivel-e-venceanderson-silva-por-nocaute.html>. Acesso em: 27 out. 2017.
ZUFFA O UFC está à beira da falência quando os dois executivos de cassinos de Las Vegas, os irmãos Lorenzo e Frank Fertitta, compraram a franquia em 2001. Com o promoter de Boxe Dana White no comando, os americanos assumiram o desafio de alavancar o UFC. Tatameonline, 2017. Disponível em: <http://tatameonline.com/a-historiado-ufc-saiba-como-a-zuffa-se-tornou-a-maior-referenciado-mma/>. Acesso em: 27 out. 2017.

Saiba como a ZUFFA se tornou a maior referência do MMA. Tatameonline, 2017a. Disponível em: $<$ http://tatameonline. com/a-historia-do-ufc-saiba-como-a-zuffa-se-tornou-amaior-referencia-do-mma/>. Acesso em: 28 out. 2017.

Recebido em: 20.07.2017

Aceito em: 23.10.2017 